\title{
Study of Atoms Arrangement in Zr-Based Bulk Metallic Glass Structure
}

\author{
W. PILARCZYK ${ }^{a, *}$ AND J. PODWÓRNY ${ }^{b}$ \\ ${ }^{a}$ Silesian University of Technology, Faculty of Mechanical Engineering, Akademicka 2A, 44-100 Gliwice, Poland \\ ${ }^{b}$ Institute of Ceramics and Building Materials, Refractory Materials Division in Gliwice, \\ Toszecka 99, 44-101 Gliwice, Poland
}

\begin{abstract}
$\mathrm{Zr}-\mathrm{Cu}-\mathrm{Ni}-\mathrm{Al}$ bulk metallic glass is an attractive alloy system for scientific research and engineering applications. Alloys from this system exhibit high strength, hardness, corrosion resistance and good glass forming ability which makes them useful in many applications. In order to successfully apply amorphous materials, it is necessary to characterize their structure and properties, which are mutually dependent. The mechanical properties of the Zr-based amorphous alloy are the result of its unique, disordered structure. In this experiment, amorphous alloy of desirable composition in the form of a plate with thickness of $2 \mathrm{~mm}$ was prepared by melting high purity $\mathrm{Zr}$, $\mathrm{Cu}, \mathrm{Ni}, \mathrm{Al}$ elements and casting into a copper mould by applying an ejection pressure. The amorphousness of rapidly solidified $\mathrm{Zr}_{55} \mathrm{Cu}_{30} \mathrm{Ni}_{5} \mathrm{Al}_{10}$ plate was examined by $\mathrm{X}$-ray diffraction and microscopic observation. These investigations revealed that the studied Zr-based sample was amorphous. Based on experimental X-ray data the pair distribution function was calculated and discussion on possible atoms arrangement was carried out.
\end{abstract}

DOI: 10.12693 /APhysPolA.129.216

PACS: 61.05.cp, 61.25.Mv, 61.43.Dq

\section{Introduction}

In the last years, the Zr-based bulk metallic glasses (BMG) have attracted attention because of their excellent glass forming ability and outstanding mechanical properties.

From the analysis of literature data it can be concluded that Zr-based bulk amorphous alloys exhibit simultaneously various characteristics such as good cast ability into bulk form, high mechanical strength and good ductility, good and precise deformability, high corrosion resistance, low coefficient of thermal expansion and high elasticity $[1,2]$.

In order to successfully apply Zr-based BMGs, it is necessary to accurately characterize their structure, thermal stability, and other properties.

At present, the atomic structures in amorphous alloys still remain unknown. It has been discovered that besides the dense random packing there are nanometer scale short-range order clusters and medium-range order clusters packing in the amorphous material. Furthermore, inside the multicomponent bulk metallic glasses atoms are efficiently packed and the structures of the amorphous alloys are the results of efficient cluster packing (ECP) [3].

The main aim of the presented work was to obtain $\mathrm{Zr}_{55} \mathrm{Cu}_{30} \mathrm{Ni}_{5} \mathrm{Al}_{10}$ alloy in an amorphous state and make attempt to examine atoms arrangement in its structure.

\section{Experimental procedure}

Zr-based master alloy ingot with compositions of $\mathrm{Zr}_{55} \mathrm{Cu}_{30} \mathrm{Ni}_{5} \mathrm{Al}_{10}$ was prepared by induction melting of

*corresponding author; e-mail: wirginia.pilarczyk@polsl.pl pure $\mathrm{Zr}, \mathrm{Cu}, \mathrm{Ni}, \mathrm{Al}$, elements in argon atmosphere. From the master alloy, plates were prepared by the pressure die casting method in an argon atmosphere. The master alloy was melted in a quartz crucible using an induction coil and pushed in a copper mould by applying an ejection pressure. The investigated material was cast in form of plate with thickness $2 \mathrm{~mm}$.

To reveal amorphous state the differential scanning calorimetry (DSC), microscopic observation (SEM and LM), X-ray diffraction (XRD) as well as diffuse scattering of X-ray and pair distribution function (PDF) were applied.

Thermal stability associated with glass transition temperature $\left(T_{\mathrm{g}}\right)$, onset crystallization temperature $\left(T_{\mathrm{x}}\right)$ and peak crystallization temperature $\left(T_{\mathrm{p}}\right)$ of the as-cast alloy was examined by differential scanning calorimetry (DSC) method using DSC 822 Mettler Toledo at a constant heating rate of $40 \mathrm{~K} / \mathrm{min}$.

The observation of the shape and size of the precipitates was carried out by means of an OLYMPUS optical microscope GX71 model. Cross-section of the test specimen by polishing and grinding on Struers Tegramin-30 and LaboPol 35 machines was prepared. The sample was etched for $5 \mathrm{~s}$.

The microscopic observation of the surface morphology of studied glassy materials cross-section was carried out by means of the Zeiss Supra 35 scanning electron microscope equipped with a chemical composition analysis detector EDS by Oxford.

X-ray diffraction experiments on Panalytical Empirian diffractometer equipped with $\mathrm{Ag}$ tube and scintillation detector were carried out. The diffraction pattern in range $5^{\circ}$ to $140^{\circ} 2 \theta$ was obtained with step $0.3^{\circ} 2 \theta$ and $82 \mathrm{~s}$ per step. The atomic pair distribution function (PDF) by RAD software was calculated $[4,5]$. 


\section{Results and discussion}

It is very difficult to obtain a Zr-based BMG in a form of plate with large sizes. Usually, the difficulties of the production of zirconium amorphous alloy are connected with the fact that the constituent elements of the analyzed materials have a high chemical affinity for oxygen, and have different melting points. For this reason, the process of producing massive metallic glasses in zirconium matrix require the use of additional technology to provide specific conditions for the melting and casting.

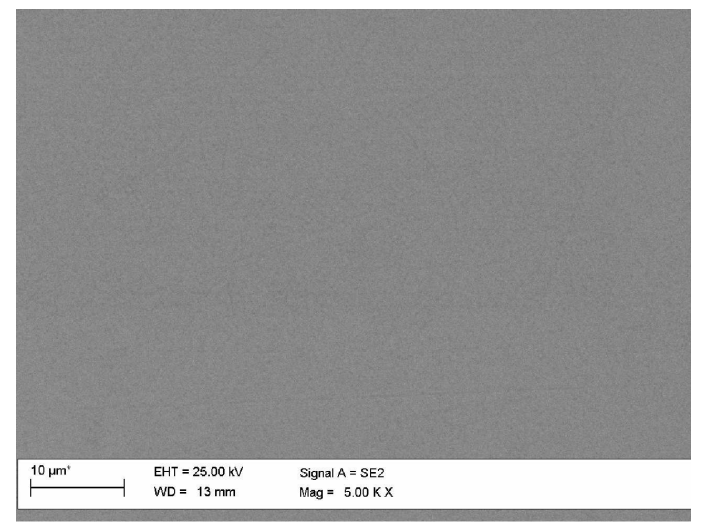

Fig. 1. Morphology of $\mathrm{Zr}_{55} \mathrm{Cu}_{30} \mathrm{Ni}_{5} \mathrm{Al}_{10}$ amorphous plate with thickness of $2 \mathrm{~mm}$ (SEM, cross-section of etched sample).

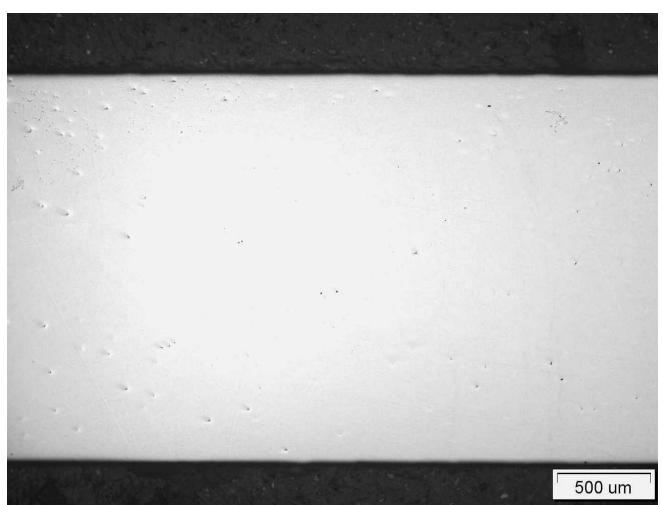

Fig. 2. Structure of $\mathrm{Zr}_{55} \mathrm{Cu}_{30} \mathrm{Ni}_{5} \mathrm{Al}_{10}$ as-cast amorphous plate (optical microscope, cross-section of etched sample).

In Figs. 1 and 2 structures of cross-section of etched as-cast amorphous plate were shown. The scanning electron microscopy (SEM) analysis gives information of the existence of "smooth" areas. No noticeable crystal were observed. "Smooth" areas of the cross-section of sample exist in the all over tested surface, whereas the some small points occur at the place of the sample in Fig. 2. These points have been identified as die marks and pore. The presented surfaces are characteristic for metallic glasses.

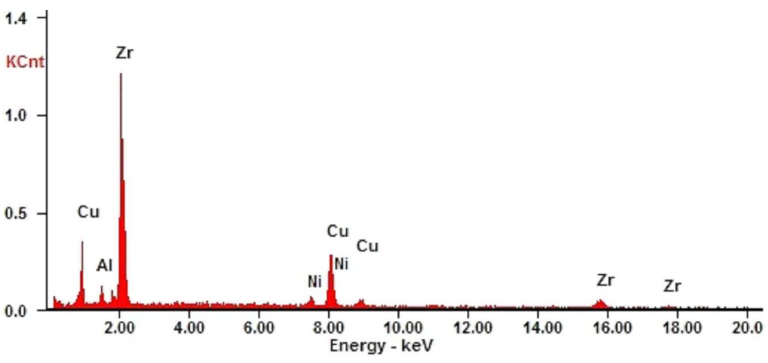

Fig. 3. EDS microanalysis of the tested plate (area from Fig. 1).

The alloy was also checked with energy dispersive spectroscopy (EDS) attachment to identify chemical composition of chosen areas. Chemical analysis of these areas show the presence of exclusively $\mathrm{Zr}, \mathrm{Cu}, \mathrm{Ni}$ and $\mathrm{Al}$ elements. The curve of the X-ray dispersive of $\mathrm{Zr}_{55} \mathrm{Cu}_{30} \mathrm{Ni}_{5} \mathrm{Al}_{10}$ alloy is presented in Fig. 3.

This sample shows a considerable glass transition process. The crystallization of the tested alloy exhibits one step process. The DSC curve measured at $40 \mathrm{~K} / \mathrm{min}$ on amorphous sample plate with thickness of $2 \mathrm{~mm}$ in ascast state is shown in Fig. 4.

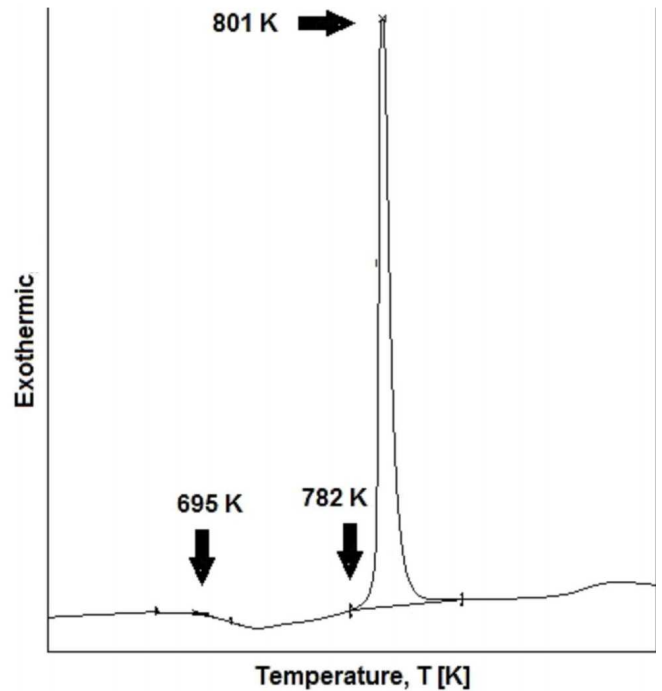

Fig. 4. DSC curve of $\mathrm{Zr}_{55} \mathrm{Cu}_{30} \mathrm{Ni}_{5} \mathrm{Al}_{10}$ alloy in as-cast state in form of plate with thickness of $2 \mathrm{~mm}$.

The distinct exothermic peak describing crystallization process of studied glassy alloy is observed. The exothermic effect includes glass transition temperature $T_{\mathrm{g}}=$ $695 \mathrm{~K}$, onset crystallization temperature at value of $T_{\mathrm{x}}=782 \mathrm{~K}$ and peak crystallization temperature at $T_{\mathrm{p}}=801 \mathrm{~K}$. The width of $\Delta T_{\mathrm{x}}=T_{\mathrm{x}}-T_{\mathrm{g}}$ is $87 \mathrm{~K}$, indicating that the alloy possesses a sufficient stability of the supercooled liquid.

In scientist's opinion, the width of supercooled liquid region is a very good glass forming ability (GFA) measure. From the analysis of literature and obtained data it can be concluded that when range of temperature $\Delta T_{\mathrm{x}}$ 
is larger, GFA is higher. $\Delta T_{\mathrm{x}}$ criterion is acknowledged through researchers in this field of science.

X-ray pattern presented in Fig. 5 showed that obtained BMGs sample was amorphous. No Bragg peaks were observed.

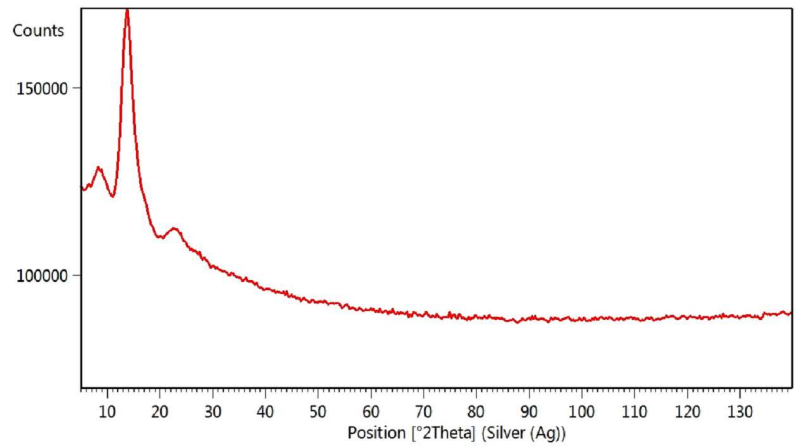

Fig. 5. X-ray pattern of $\mathrm{Zr}_{55} \mathrm{Cu}_{30} \mathrm{Ni}_{5} \mathrm{Al}_{10}$ alloy in ascast state in form of plate with thickness of $2 \mathrm{~mm}$.

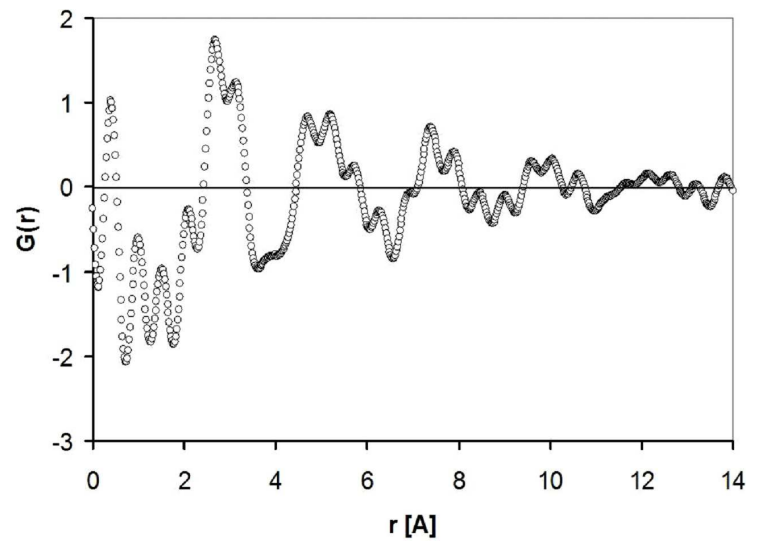

Fig. 6. $\mathrm{PDF}$ of $\mathrm{Zr}_{55} \mathrm{Cu}_{30} \mathrm{Ni}_{5} \mathrm{Al}_{10}$ alloy in as-cast state in form of plate with thickness of $2 \mathrm{~mm}$.

Values of the radii of coordination spheres obtained for $\mathrm{Zr}_{55} \mathrm{Cu}_{30} \mathrm{Ni}_{5} \mathrm{Al}_{10}$ amorphous alloy from PDF presented in Fig. 6 are: 2.68, 3.12, 4.68, 5.20, 5.71, 7.37, $7.88 \AA$.

The radii of the first and second correlation spheres indicate that its value is characteristic for $\mathrm{Zr}-\mathrm{Cu}$ and $\mathrm{Zr}-\mathrm{Zr}$ atomic distances (Table I).

\section{TABLE I}

Values of measured based on $\mathrm{PDF}$ and expected atomic distances in $\mathrm{Zr}_{55} \mathrm{Cu}_{30} \mathrm{Ni}_{5} \mathrm{Al}_{10}$ alloy for first and second coordination spheres.

\begin{tabular}{l|c|c}
\hline \hline & Measured $[\AA]$ & Expected $[\AA]$ \\
\hline $\mathrm{Zr}-\mathrm{Cu}$ & 2.68 & 2.88 \\
$\mathrm{Zr}-\mathrm{Zr}$ & 3.12 & 3.20
\end{tabular}

Assuming that $\mathrm{Zr}$ is central atom first correlation sphere should be preferentially occupied by $\mathrm{Cu}$ and second by $\mathrm{Zr}$ atoms.
Obtained PDF (Fig. 6) is similar to those obtained by Sun et al. in papers $[3,6]$, especially BMGs with composition $\mathrm{Zr}_{50.7} \mathrm{Cu}_{28} \mathrm{Ni}_{9} \mathrm{Al}_{12.3}$. This metallic glass have similar $\mathrm{Zr}$ to $\mathrm{Cu}$ ratio to that presented in this work equal to 1.81 and 1.83 , respectively. Mentioned authors noticed that first peak around 2.7 $\AA$ on PDF arises when $\mathrm{Cu}$ concentration in glass increases due to increasing number of $\mathrm{Zr}-\mathrm{Cu}$ pairs. Consequently second peak around $3.12 \AA$ decreases due to decreasing number of $\mathrm{Zr}-\mathrm{Zr}$ pairs. It corresponds also to improving GFA with increasing of $\mathrm{Cu}$ concentration in $\mathrm{Zr}-\mathrm{Cu}-\mathrm{Ni}-\mathrm{Al}$ BMGs. Mentioned authors proposed based on RMC method of local structure modeling model in which density fluctuations and clusters with dense and loose packing volumes appear [6]. They suggest that in these inhomogeneous in atomic scale glasses, dense and loose packing clusters are responsible for GFA. Conclusion of mentioned authors seems to be confirmed by negative results of trial undertake in this work of finding homogeneous local structure of $\mathrm{Zr}_{55} \mathrm{Cu}_{30} \mathrm{Ni}_{5} \mathrm{Al}_{10}$ alloy by modelling in real-space via PDF Rietveld refinement in which possibility of local structure closely related to high temperature forms of $\mathrm{Zr}-\mathrm{Cu}-\mathrm{Ni}-\mathrm{Al}$ alloys was searched.

\section{Conclusions}

The Zr-based amorphous alloy in form of plate with good glass forming ability was produced by die pressure casting method. The DSC analysis indicates that the alloy possess a sufficient stability of supercooled liquid. The microscopic examination revealed smooth inner surfaces of the test pieces. The investigation methods revealed that the studied as-cast alloy was amorphous.

Attempts to find local structure based on the Rietveld modelling in real-space did not succeed probably due to appearance of atoms clusters with different ordering in tested amorphous alloy.

\section{Acknowledgments}

This work was partially supported by National Science Centre (NCN) (project no. 2011/01/D/ST8/07327).

\section{References}

[1] A. Inoue, Sci. Rep. Res. Tohoku A 42, 1 (1996).

[2] J.F. Löffler, Intermetallics 11, 529 (2003).

[3] Y.L. Sun, D.D. Qu, Y.J. Huang, K.-D. Liss, X.S. Wei, D.W. Xing, J. Shen, Acta Mater. 57, 1290 (2009).

[4] V. Petkov, J. Appl. Crystallogr. 22, 387 (1989).

[5] W. Pilarczyk, J. Podwórny, Solid State Phenom. 203-204, 386 (2013).

[6] Y.L. Sun, D.D. Qu, Y.J. Sun, K.-D. Liss, J. Shen, J. Non-Cryst. Solids 356, 39 (2010). 